\title{
Local climate action plans in climate change mitigation \\ examining the case of Denmark
}

Damsø, Tue Noa Jacques; Kjær, Tyge; Christensen, Thomas Budde

\section{Published in: \\ Energy Policy}

DOI:

10.1016/j.enpol.2015.11.013

Publication date:

2016

Document Version

Peer reviewed version

Citation for published version (APA):

Damsø, T. N. J., Kjær, T., \& Christensen, T. B. (2016). Local climate action plans in climate change mitigation: examining the case of Denmark. Energy Policy, 89, 74-83. https://doi.org/10.1016/j.enpol.2015.11.013

\section{General rights}

Copyright and moral rights for the publications made accessible in the public portal are retained by the authors and/or other copyright owners and it is a condition of accessing publications that users recognise and abide by the legal requirements associated with these rights.

- Users may download and print one copy of any publication from the public portal for the purpose of private study or research.

- You may not further distribute the material or use it for any profit-making activity or commercial gain.

- You may freely distribute the URL identifying the publication in the public portal.

\section{Take down policy}

If you believe that this document breaches copyright please contact rucforsk@kb.dk providing details, and we will remove access to the work immediately and investigate your claim. 


\title{
Local Climate Action Plans in climate change mitigation - examining the case of Denmark
}

\author{
Tue Dams $\emptyset^{*, a}$, Tyge Kjæra $\&$ Thomas Budde Christensen ${ }^{a}$ \\ a Department of Environmental, Social, and Spatial Change (ENSPAC), Roskilde University (RUC), \\ building 12.1, P.O.-box 260, DK-4000 Roskilde, Denmark. \\ *Corresponding author: tnjd@ruc.dk; +45 2022-1373
}

\section{Highlights:}

- Widespread adoption of Climate Action Plans among Local Governments in Denmark

- Local plans cover two-thirds of Danish emissions and have slightly lower targets

- Local plans have a high overall coverage with variation in scope and target level

- Indicates potential of including all local actors in integrated governance system

- Integrated governance system should improve plans by regional supporting structures

Abstract: The article examines the climate action plans (CAPs) of local governments (LGs) in Denmark. Applying a quantitative content analysis approach, all Danish LG action plans within the climate and energy field has been collected and coded, giving insight into the extent of LG CAPs. We assess the extent, targets and scope of LG CAPs and find that Danish LGs are highly involved in mitigation activities with a widespread CAP adoption and an overall high degree of sectoral coverage on base year accounts and action plans, albeit with some significant shortcomings. If current LG CAPs were to form the basis of a decentralised climate governance system, some improvements in target level and sectoral coverage should be implemented. The utilization of regional supporting structures facilitating a gradual improvement seems especially promising. In addition the research points to the significant mitigation potential of considering the full spectrum of local government actors, not simply the pioneers and how local CAPs outside urban pioneers require additional local policy framing to succeed. Focusing on the mutual benefits for national and local actors of an integrated planning system, and the multiple benefits locally will be key in motivating further action.

Keywords: Municipalities, Local Governments, Renewable Energy, Mitigation, Governance, Greenhouse gas

\section{Introduction}

Can local planning provide a significant and relevant contribution to climate change mitigation? The objective of this research is to assess the relevance of local climate action planning in mitigating global climate change, by examining the propagation and scope of local climate action plans (CAPs ${ }^{1}$ ) in Denmark.

\footnotetext{
${ }^{1}$ Abbreviations: CAP: Climate Action Plan, CoM: Covenant of Mayors, DN: Danish Nature Conservation Organisation, LA21: Local Agenda 21, LG: Local Government, LGDK: Local Government Denmark.
} 
The institutional anchoring of Local Governments (LG) work towards global sustainability, including climate change mitigation, can be firmly based on the 1992 Rio Earth Summit's adoption of the Agenda 21 plan of action. In this action plan, the United Nations (UN), and the majority of the countries in the world, acknowledge the key role played by local governments (Musco, 2010: 59). "Because so many of the problems and solutions being addressed by Agenda 21 have their roots in local activities, the participation and cooperation of Local authorities will be a determining factor in fulfilling it's objectives." (UN, 1992: pt. 28.1). Following this affirmation, chapter 28 of the declaration appeals to local authorities to engage in developing local plans for sustainable development, an appeal that has since been reaffirmed by all the subsequent world conferences on sustainability (Lafferty, 2001:1; UN, 1997: pt. 12; UN, 2002: pt. 167; UN, 2012: pt. 42). In the context of global climate change, the need for immediate action as well as the lack of such action from major emitters; several authors point to the frameworks and planning traditions established by Local Agenda 21 (LA21), and the role of local governments in addressing the problem bottom-up (Fudge \& Peters, 2009: 103; Holm, 2007: 176; Musco, 2010: 74). "It was therefore argued that local government agencies could now perform a role as a catalyst in linking top-down agendas and bottom-up delivery through their influence 'as major players in the local economy: their role as employers, purchasers of goods and services and local regulators', meant that they were ideally placed to provide a more strategic approach to the governance of global risk." (Fudge \& Peters, 2009: 105). In attempting to mitigate global climate change through local action, it is essential to assess whether local governments are willing to act, and whether those actions can be considered relevant contributions to mitigating the problem at hand.

An initial review would suggest that local governments exhibit a willingness to take action on global climate change. One indicator of this are the numerous international networks that has been formed through which thousands of local governments have pledged to take ambitious voluntary action on climate change, clearly showing that local governments are picking up the gauntlet in the absence of agreement in the international community (Kern \& Alber, 2008: 184; Bulkeley, 2010: 232f; Corfee-Morlot, 2009: 29; Bulkeley \& Betsill, 2005: 42). Local governments have worked with initiatives to mitigate global climate change since the early 1990's in parallel with the LA21 sustainability work, but in recent years the number of initiatives have grown exponentially (Bulkeley, 2010: 231f). In a Danish context studies show a similar trend of increasing interest in the mitigation activities among local governments, and in 2009 Local Government Denmark (LGDK) called upon the state to revisit the division of tasks on energy planning among the different levels of government, with the aim of assigning additional tasks to Danish municipalities (MM, 2010: 17; Hoff \& Strobel, 2013: 3; Sperling et al., 2011: 1341; LGDK, 2009: 6).

With regards to the relevance of those actions, the Agenda 21 action plan, and with it the world community, clearly recognize the key role played by LGs in addressing sustainability problems (UN, 1992: pt. 28.1). In fact global systems thinking often run the risk of discounting that global changes are always locally 'made' and enacted (Coenen et al., 2012: 975). Looking more specifically at 
climate change mitigation, climate change is undeniably a global issue; the driving forces however, can generally be considered local, in the sense that they are a result of activities (and associated emissions) in a given place (Aall et al., 2007: 84; Wilbanks \& Kates, 1999: 610ff, 615; Bai, 2007: 18). In this way local action can be considered critical as LGs can influence a number of the key sectors in mitigating the problem (Musco, 2010: 67f). Additionally centralized decisionmaking will likely lead to either information impoverishment or overload, as the transmission and utilization of information on local characteristics to central decision makers will be difficult if not impossible and infer a high transaction cost (Scharpf, 1993: 135). By limiting the scope of enquiry, e.g. by local as opposed to national energy planning, more aspects of a given planning process and detailed knowledge of the local area can be taken into account, providing a significant potential for optimal energy planning (Crossley \& Sørensen, 1983: 9f). This potential is further exacerbated by the localised nature of renewable energy (RE) resources. As RE resources are significantly more dispersed and difficult to store and transport than fossil fuels (Smil, 2010), a more distributed generation and correspondingly a more distributed planning system may be a better 'fit' than the traditional national planning system. However some limitations in a local approach to climate change mitigation can be identified as well, in particular the voluntary nature of the commitment, leading to largely symbolic targets that has only seldom been implemented fully (Musco, 2010: 74; Bulkeley, 2013: 74). Alongside implementation difficulties, the voluntary nature of early commitment has resulted in a large variation with regard to target, scope and quality of LG CAPs (see e.g. Wheeler, 2008: 483; Rice, 2013: 333; Hoff \& Strobel, 2013: 6; Dixon \& Wilson, 2013: 673f). Some variation is desirable as customization of measures to local mitigation options is one of the key arguments for increased local action (Lutsey, 2008: 674). However, if variation is due to shortcomings in the CAPs as opposed to customization this may greatly inhibit the effectiveness of local action. Kousky and Schneider note that municipalities define, and thereby calculate emissions in varying ways (Kousky \& Schneider, 2003: 363). A result of this variation in CAP content is variation in CAP scope, possibly leading to the omission of key aspects from the planning process as well as excessive focus on other measures, which in turn may yield suboptimal results. Local programs are often characterised by grabbing the 'lowhanging fruit', and not the more challenging or long-range aspects of the system transition (Rice, 2013: 333; Sperling et al., 2011: 1344). The lack of a long-term perspective, as well as a coherent and coordinated effort, runs the risk of creating externalities and producing a suboptimal result (Giddens, 2009: 128). These aspects relate to the inherent scale issues associated with addressing a global problem locally. This is partly a conceptual issue, in the sense that the GHG emissions influenced by local decision makers do not necessarily fit with the emissions driven by local actions (Wilbanks \& Kates, 1999: 605, 616; Bai, 2007: 18). And it is partly motivational, as people are asked to take local action on a global problem, distant to them in both time and place (Wilbanks \& Kates, 1999: 618; Bai, 2007: 19). In this study we wish to examine whether local authorities in Denmark exhibit a widespread adoption of climate action plans and whether their actions constitute an adequate and relevant contribution to climate change mitigation in terms of scope and target level. By including not simply frontrunner municipalities, but all local authorities in Denmark, we aim to discuss the 
possibilities and advantages of including local authorities in a more decentralised governance system for climate change mitigation.

\subsection{The extent of local climate action}

The role of local governments, as important actors in sustainable development and climate change mitigation, has received increased attention since the mid1990s (Sperling et al., 2011: 1339; Bulkeley, 2010: 231). Early research within this field, and indeed much research to date, has focused on studying individual or small sets of cases (Broto \& Bulkeley, 2013: 92f; Bulkeley, 2010: 248; Rice, 2014: 334). This has led some researchers to conclude that "...there is a need for further comparative research using significant numbers of cases." (Bulkeley, 2010: 248). Subsequently a number of comparative studies have attempted to address this caveat in the research community, however their research interest in explaining the variation in and emergence of local action have resulted in studies primarily focused on large cities and urban centres (cf. Dixon \& Wilson, 2013: 664; Broto \& Bulkeley, 2013: 93) or on members of local government networks (cf. Rice, 2014: 333; Wheeler, 2008: 481; Gore, 2010: 28). These are valuable and highly relevant research areas, they do not however facilitate a discussion on the overall relevance of local action, as only the pioneering local authorities is part of the study. A smaller group of studies have included a wider circle of local authorities; all of these however apply a survey methodology, in which participation is likely skewed towards the ones taking action and the ones participating will likely complete the questionnaire with some interpretive bias (cf. Pitt \& Basset, 2013: 2; Salon et al., 2014: 67; Bedsworth \& Hanak, 2013: 668, and in a Danish context Hoff \& Strobel, 2013: 4; CONCITO, 2010; Energiforum, 2014).

To address these aspects we apply a comparative content analysis approach and include all local authorities in Denmark. By including not simply urban frontrunners, but all LGs in a country, we can gain a better understanding of the dissemination and application of CAPs among municipalities not traditionally expected to engage in climate action. In furthering a decentralised planning regime this insight is key, making it possible to assess the full extent and contribution by LGs in a national context and thereby the relevance of local CAPs in facilitating change.

\section{Methodological approach}

This article examines the relevance of local action as a contribution to national climate change mitigation. The relevance of local action depends on the extent of their willingness to act and whether their actions are adequate in scope and coverage. The assessment of these aspects is split into two sections: One exploring the willingness to act by the extent, variation and target level of LG CAPs; and one assessing CAP sufficiency by scope and coverage of greenhouse gas (GHG) accounts and the planned mitigation actions.

\subsection{Research Questions}

- RQ1: What are the extent, variation and target level of LG CAPs in Denmark?

- RQ2: How is the scope and coverage of GHG accounts and mitigation actions of LG CAPs? 
Denmark is a highly relevant case country for this study because Denmark in many ways is a frontrunner in local climate planning. Denmark has undergone a significant energy transition in the period since the mid 1970s involving, amongother, a significant decentralisation of energy production (Sperling et al., 2011: 1339f; Chittum \& Østergaard, 2014: 466f). Currently endowed with the largest penetration of distributed generation capacity in the industrialised world (Sauter \& Bauknecht, 2009: 156) Danish energy policy confer significant autonomy and flexibility to local energy actors (Chittum \& Østergaard, 2014: 466) Denmark can be considered among the most progressive countries on climate change mitigation, in particular with regards to the involvement of local actors. Studying Danish climate action planning thereby provides an indication of the direction that local climate action may take in other countries in the years to come.

\subsection{Data collection}

The study applies a comprehensive cross-sectional literature review with a total of 436 documents for 103 local authorities, spanning all 98 municipalities and 5 regions in Denmark, eliminating the necessity of examining sampling bias (Andersen, 2010: 111ff). Data collection has been conducted exclusively by the authors in two separate stages: First utilizing internet search engines for uncovering publicly available actions plans, applying a predetermined sequence of search terms coupling the municipalities name with a number of key words. This was supplemented with a review of the local authority website to uncover potential additional action plans not visible in search engine results. Secondly employing e-mail enquiries for the local authorities for whom no action plan appeared in the online search. The use of internet search engines as the primary means of data collection has its limitations, as some action plans may be inaccessible to standard search queries (Broto \& Bulkeley, 2013: 96). We have attempted to remedy this by the subsequent website review and e-mail enquiry, but there will undoubtedly be LG CAPs not included in this survey due to inaccessibility.

\subsection{Data processing $\&$ analysis}

The data has been processed utilizing a quantitative content analysis technique, by which key characteristics has been codified following a predetermined coding manual (Appendix A). Based on our research interests and prior knowledge of the field, an initial coding scheme was developed and applied to a pilot study of 42 plan documents. Subsequently the coding scheme was revised and documents from the pilot study recoded. The data has been entered manually into an excelbased coding scheme with a line of data for each LG, in which the information from the different CAP documents for the respective LG has been summarized. The sheet includes information on the targets and scope of the action plan, the number of documents and plan elements as well as a series of categorical variables on population, GDP, network memberships, geographical location and urbanity in order to assess correlations. The data was analysed using univariate analysis in mapping overall variation and then bivariate analysis in assessing relationships among variables and thereby patterns of variation (Andersen, 2010: 193f). 


\subsection{Limitations}

This study is focused on climate change mitigation in Denmark, and therefore excludes adaptation aspects related to local planning. In Denmark, as in many other industrialised nations, emissions related to the combustion of fuels are the dominant source of GHG emissions (Nielsen et al., 2014: 16), as well as being the emission source over which local authorities exert the largest influence. As a result climate change mitigation, and energy transition, are often combined, or even conflated in local CAPs, necessitating an integrated study of climate and energy plans. In the following the concepts of climate and energy plans are used interchangeably as this is often the reality in local CAPs.

Another limitation is the necessary lack of depth due to the large sample and the focus on plan documents, inhibiting the possibility of assessing implementation performance. This is a key limitation of this study as a CAP is only the premise for action, and it does not necessarily follow that the plan is implemented properly. We are able to discuss variation in the target, scope and extent of LG CAPs, but not performance or commitment level beyond policy formulation and adoption.

\section{Results and Discussion}

The focus of the research reported in this article is assessing the relevance of local action by the targets and scopes of LG CAPs. As a result the following analysis and discussion is split into these two topics.

\subsection{Targets}

3.1.1. Extent of climate action planning

Assessing the extent and relevance of LGs climate action planning depends first and foremost on the presence of an action plan. However the coverage and target level of the CAPs in question is an integral part of assessing the relevance of local action as well. For this reason we have developed a composite measure, capable of displaying differences in plan presence, scope and target level. Figure 1 shows a map of Denmark, in which the 98 municipalities are colour coded to show the extent of climate action planning. 


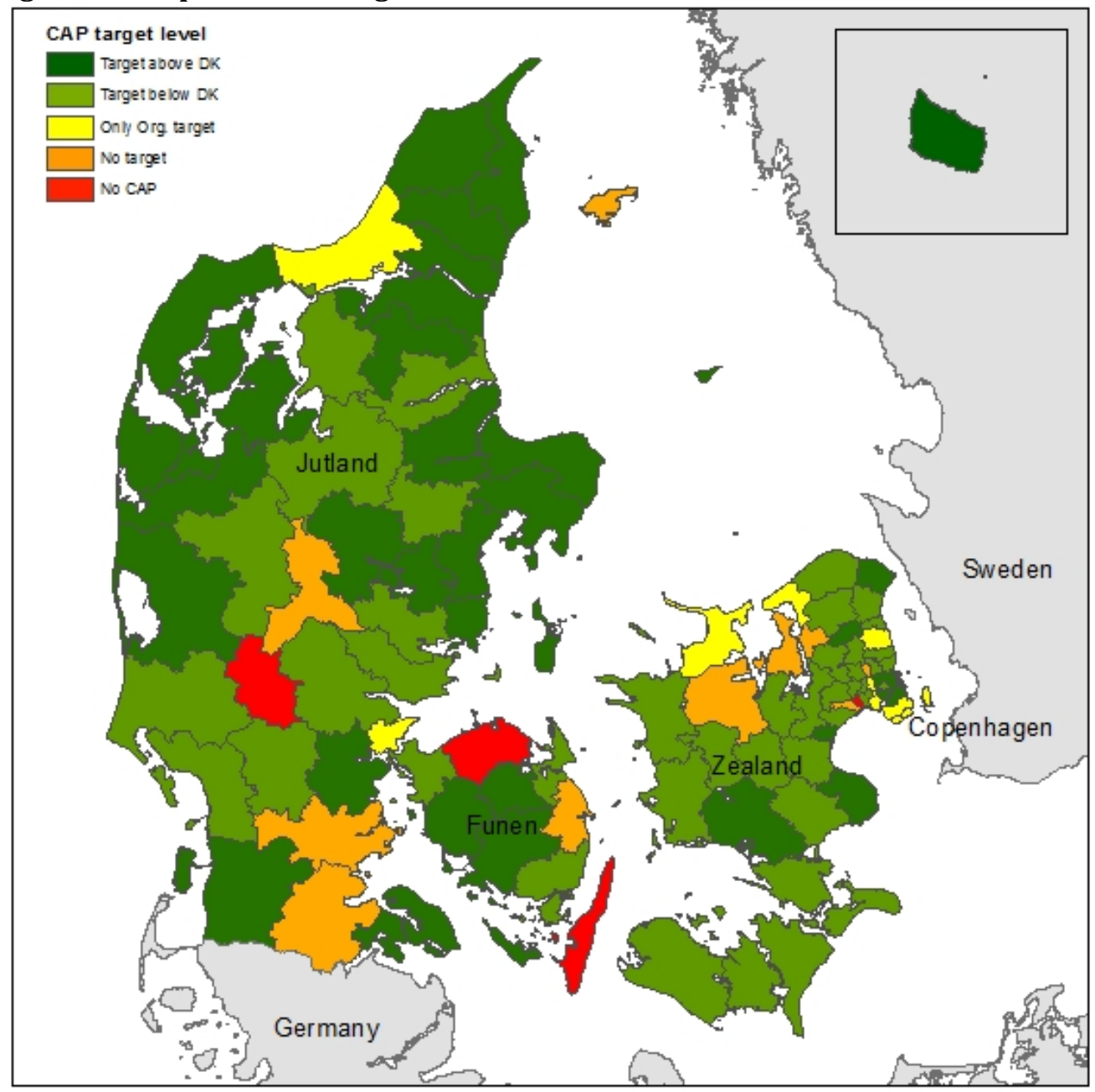

Source: Based on the authors coding study. The underlying map is utilizing data from the Danish Geodata Agency, Kort10, January 2015 (Danish Geodata Agency, 2015). In the figure Danish municipalities are split into groups based on their level of climate action, where the lowest performing group (red) has no action plan at all, the second (orange) has no quantified target, the third (yellow) has a target for only the organisational emissions and the two highest performing groups (light and dark green) have community targets below and above the national Danish target levels, respectively.

The lowest performing group (red) has no CAP documents at all, whereas the second group (orange) has a climate action plan, but no discernible quantified mitigation target. The third group has a mitigation target, however only spanning the municipal organization, whereas the two top performing groups has a CAP including quantified targets for the community scope. The light green group has a target below the national reduction target level of $40 \%$ in the short term (target year $\leq 2035$ ) or $80 \%$ in the long-term (2036-2050)(The Danish Government, 2013: 10). The top-performing group (dark green) has a target equal to or above the national target levels for the community scope. $79 \%$ of local governments $(n=81)$ have a quantitative community scope target, the largest share of which has a target below the national average $(n=44)$ and the remaining a target equal to or above the national average $(n=37)$. Of the remaining $21 \%, 9 \%(n=9)$ has an organisational target, $9 \%(n=9)$ has an action plan with no quantitative target and only $4 \%(n=4)$ has no discernible action plan at all, indicating a significant extent of climate action planning among LGs in 
Denmark. Overall the clear majority of Danish LGs have a high performance level, with regards to CAP scope and target level. If we compare these results to surveys of local climate action in Denmark a development pattern can be observed. CONCITO found that $57 \%$ of municipalities had a reduction target for the community scope in 2010, where a study by Hoff and Strobel finds that $77 \%$ of municipalities include the community scope in their action plan in 2011, and Energiforum that 74-82\% of municipalities had an action plan at the end of 2013 (CONCITO, 2010: 8; Hoff \& Strobel, 2013: 6; Energiforum, 2014: 4). This could indicate a significant rise and subsequent stabilization in the number of active municipalities in the period after 2010, which is in line with CONCITOs results that about half the municipalities without a GHG account in 2010 was developing one (2010: 9). Additionally this corresponds with the assertion that academic and policy communities have shifted their focus to the local level in the wake of the disappointing results of the $15^{\text {th }}$ Conference of the Parties to the United Nations Framework Convention on Climate Change in 2009 (Hoff \& Strobel, 2013: 3).

These results clearly exhibit a widespread adoption of fairly comprehensive and ambitious action plans among Danish LGs, and as such a significant willingness to act on addressing this challenge. In the following we will further assess whether key structural factors can explain the variation in CAP presence, and subsequently whether the target level and scope of the CAPs sufficiently addresses the mitigation task.

\subsubsection{Variation}

In the following section we will assess whether differences in CAP presence and target level can be attributed to the presence of different driving forces, such as the degree of urbanization, political affiliation and demographic development. The relationship between climate action and political affiliation has been the topic of numerous studies with mixed results (e.g. Hoff \& Strobel, 2013: 3; Bedsworth \& Hanak, 2013: 670; Bulkeley, 2010: 244). The other two indicators have been selected due to their correlation with municipality size, income level and unemployment, several of which has been indicated to be affecting the level of action (Hoff \& Strobel, 2013: 3; Bedsworth \& Hanak, 2013: 670). A municipality's degree of urbanization indicates it's relative size, population density and economic structure, which speaks to the possibility of expanding renewable energy, as well as the municipal income level, greatly affecting the financial capability of investing in climate change mitigation. At the same time, Denmark is experiencing a significant migration from rural to urban municipalities, further exacerbating this pattern. Looking at patterns of variation, there are some differences among different groups of actors, however not in a way that decisively point to a clear determining factor behind high levels of climate action. Figure 2 summarizes the variation for the different categories.

Figure 2: Variation in CAP presence $\&$ target level 


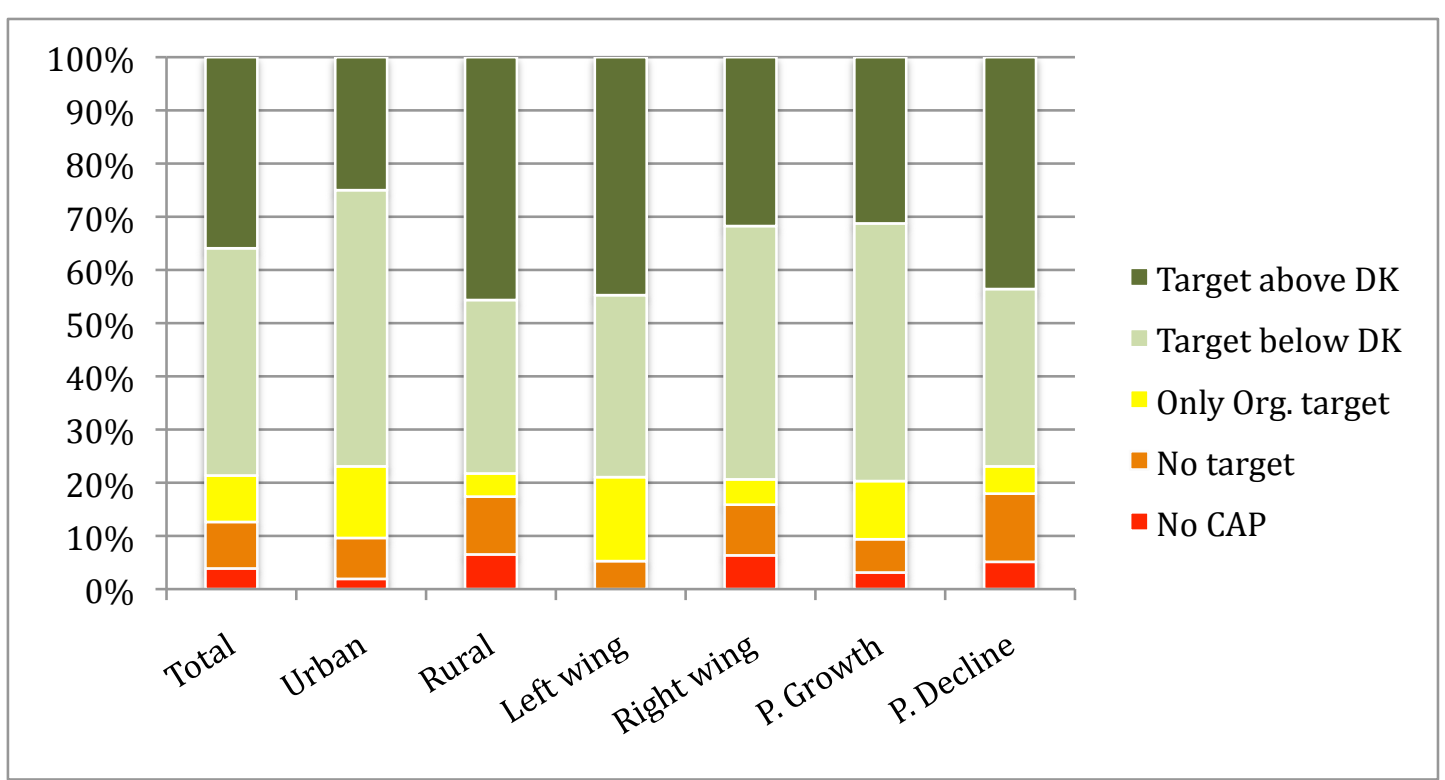

The figure compares the level of climate action from figure 1 with a number of indicators to assess performance correlation. Following the column with overall distribution (total), is two columns in which municipalities are grouped based on their rural degree (Urban \& Rural), two columns in which they are grouped based on their political affiliation (Left/right wing mayor) and finally two columns with groupings based on whether they expect a population growth or decline in coming years.

Adopting the same groupings and a similar colour-coding scheme as figure 1 , we distinguish between five groups of actors with no CAP, no target, only an organisational target or a community scope target below or above the national mitigation goals, respectively. Following the column with the overall distribution are two columns in which the municipalities are grouped based on a composite measure of their rural degree, following a simplified version of the classification of municipalities in the Danish rural district program (Ministry of Housing, Urban \& Rural Affairs, 2012: 10f; DJF, 2007: 2-4). While there is a larger concentration of municipalities with a community scope target below the national target level in the urban municipalities and of the targets above the national level in the rural municipalities, the overall share of municipalities with a community scope target vary only slightly between $77 \%$ and $78 \%$. In addition although a larger share of rural municipalities have a community scope target above the national target level (46\% rural, 25\% urban), there is a slightly larger share of urban municipalities with an emission reduction target, if all target types are accounted for (90\% urban, $83 \%$ rural). This could indicate that the rural degree exhibits some correlation with the presence of a CAP (2\% urban, $7 \%$ rural), but a significantly larger correlation with the target level and typology. Turning subsequently to political affiliation the following two columns summarize the results for municipalities with left wing and right wing mayors respectively ${ }^{2}$. Left wing municipalities show a higher target level, having a larger share of municipalities with an above average community target, a larger share with an organisational target and smaller shares with no target and no CAP. The

\footnotetext{
2 Following the Danish distinction. Denmark has a multi-party system, in which the mayors affiliated with the Socialist-Peoples party, the Social Democrats and the Social-liberal party are considered left-wing and the mayors affiliated with the Liberal Party and the Conservatives are considered right-wing.
} 
slightly higher extent of climate action among left wing municipalities is to be expected, and although clearly to some extent a relevant indicator it only points to a marginal variation as e.g. the total share of municipalities with a community scope target is the same for both groups. This is somewhat in line with the findings by Hoff \& Strobel who find no evidence supporting partisan differences in target levels (2013: 9). In a simultaneous study of LG climate action in California, Bedsworth \& Hanak point to partisan affiliation holding a stronger sway in a 2008 survey than the subsequent 2010 survey (2013: 673) suggesting that it may be a relevant indicator of early adopters, and then waning in importance as the adoption of CAPs becomes more widespread. With a widespread adoption of CAPs in Denmark, and only a marginal variation corresponding with partisan affiliation, this is in line with the results of this study. In the final two columns of the table, municipalities are grouped based on whether they are expecting a population growth or decline in 2014-2040. As can be seen there is no clear indication that this affects the target level, however there is a slightly higher level of top-performers among municipalities with a projected decline in population, which correlates with the high share of rural municipalities among the high performers.

Although variation among the different indicator groupings can be found, none fully explain the pattern of CAP extent and seem more related to target and CAP typology than CAP presence. A possible explanation of this could be that CAP presence has developed into a political necessity for Danish LGs, however that the development is based on differing drivers. In a time marked by financial austerity measures LGs may face difficulties in simply promoting climate change mitigation by investing in technology or hiring new personnel; and as a result apply new forms of governance and partnerships, often requiring an issue linkage (Dixon \& Wilson, 2013: 664; Hoff \& Strobel, 2013: 4). This strategy of linking climate issues to more pressing local issues is well known, but require the existence of a local issue that can serve as basis for addressing climate change mitigation (Bai, 2007: 26). In a Danish context the possibility of job creation for outer municipalities with a declining population, could be one of these local hooks. This would correspond with the findings of Salon et al., that the framing of local climate action differ depending on the city; where cities with residents strongly supporting climate action in it's own right, framed successful policy proposals in terms of environmental goals, and cities lacking such support framed successful policy proposals by addressing more immediate local problems (Salon et al., 2014: 76). This indicates, “...that successful local climate action requires local climate policy entrepreneurs who understand their community well enough to choose and frame their policy proposals so that they will be locally attractive." (Salon et al., 2014: 77). This relates to the call for customization of local action, where successful local action is framed to address local issues, and utilize local opportunities for doing so. Examples include Ringkøbing-Skjern municipality, one of the rural municipalities in western Jutland expecting a population decline. Their action plan contains a target of becoming $100 \%$ self-sufficient with renewable energy by 2020 , largely based on local businesses (RKSK, 2011). Similarly Thisted municipality in Northern Jutland has a target of being the leading European municipality in mitigating climate change and phasing out fossil fuels by 2025 and in doing so creating a fruitful local development (Thisted, 2009: 5, 9f). In these cases rural 
municipalities create jobs by utilizing their RE potential, whereas some urban municipalities with a higher population density, appear to focus more on their organisational emissions, as in e.g. Tårnby municipality (Tårnby, 2010: 3). These results are mirrored by a study on community energy planning in Canada, finding that smaller and more remote communities are more willing to plan for the introduction of renewable energy (St. Denis \& Parker, 2009: 2088, 2093).

A final interesting aspect on the topic of CAP variation is whether membership of local government networks, such as the Covenant of Mayors, act as an indicator of CAP presence. In Denmark there are 37 signatories to the Covenant of Mayors, one of which is an inter-municipal cooperative arrangement covering five municipalities, bringing the total group of municipalities covered by the Covenant of Mayors to 41 (EUMayors.eu, 2015b). Including members of other networks, the total number of municipalities with a community scope commitment is 43 (Greencities.dk, 2015b). Except for one municipality taking part in the inter-municipal membership of the Covenant of Mayors with no CAP and another with only an organisational target, all of these municipalities have a CAP with a community scope target split somewhat equally between targets above and below the national target level. While the majority of network members do have CAPs and community scope targets, so do approximately 40 other Danish LGs with no such commitments, indicating that network membership is not the key driver of local action. The Covenant of Mayors have had great success in promoting a significant expansion of local action across Europe, however the associated reporting requirements and harmonization of best practice approaches (cf. Kramers et al., 2013: 1285) may be incompatible with formulating policies for the local context. While providing a climate action lever for some LGs, we have yet to see whether the Covenant can provide the basis for an all-encompassing decentralised GHG planning regime.

\subsubsection{Target level}

In assessing the targets of local CAPs, we should start by distinguishing between different types of CAP targets. The Mitigation Goal Standard distinguish between four different types of emission reduction goals (GHG protocol, 2015: 13; 35f):

1. Base year emissions goal: For which a reduction target is set, relative to a base year level.

2. Fixed-level goal: For which an absolute level of emissions in a target year is set (e.g. carbon neutrality).

3. Base year intensity goal: For which an emission intensity target (GHG/unit of another variable) is defined relative to base year emissions.

4. Baseline scenario goal: For which a reduction target is defined relative to a baseline projection of emissions.

Additionally LGs may define CAP targets in other terms than GHG reduction, such as a target share of renewable energy or energy efficiency (cf. Carbonn, 2014: 19). The base year emissions goal is by far the most widespread among Danish LGs with the clear majority of LG CAPs defining a reduction target as a share of base year emissions. The fixed-level goal has some propagation with five municipalities aiming towards becoming completely free of fossil fuels and fifteen targeting carbon neutrality, whereas only four municipalities define their target as emissions/capita, the only intensity goal applied by Danish LGs. In 
addition 16 municipalities have a target specifically for renewable energy promotion. The clear majority of community scope targets are defined as singleyear goals (reductions by a single future year), whereas the clear majority of organisational targets are multi-year goals, accumulating annual reductions (e.g. 2\% p.a.)(GHG Protocol, 2015: 12). This is likely due to the nature of LG commitments, where organisational targets are defined in accordance with the climate municipality agreement, and community scope targets are inspired by e.g. the Covenant of Mayors (DN, 2015; EUMayors.eu, 2015).

Looking more specifically at the target level of community scope GHG reduction targets, figure 3 summarize the number of targets by the target level and target year. As can be seen the majority of the targets can be found between 2020 and 2030 , whereas the target level for these years are highly varied. Conversely all targets after 2030 are for $100 \%$ and all targets before 2020 are for no more than $25 \%$. The most frequent target is $20 \%$ in 2020 shared by 20 municipalities, followed by a target of $100 \%$ in 2050 (11 municipalities), 100\% target without a target year ( 9 municipalities), 100\% by 2030 ( 6 municipalities) and $100 \%$ by 2025 (5 municipalities).

Figure 3: Target level

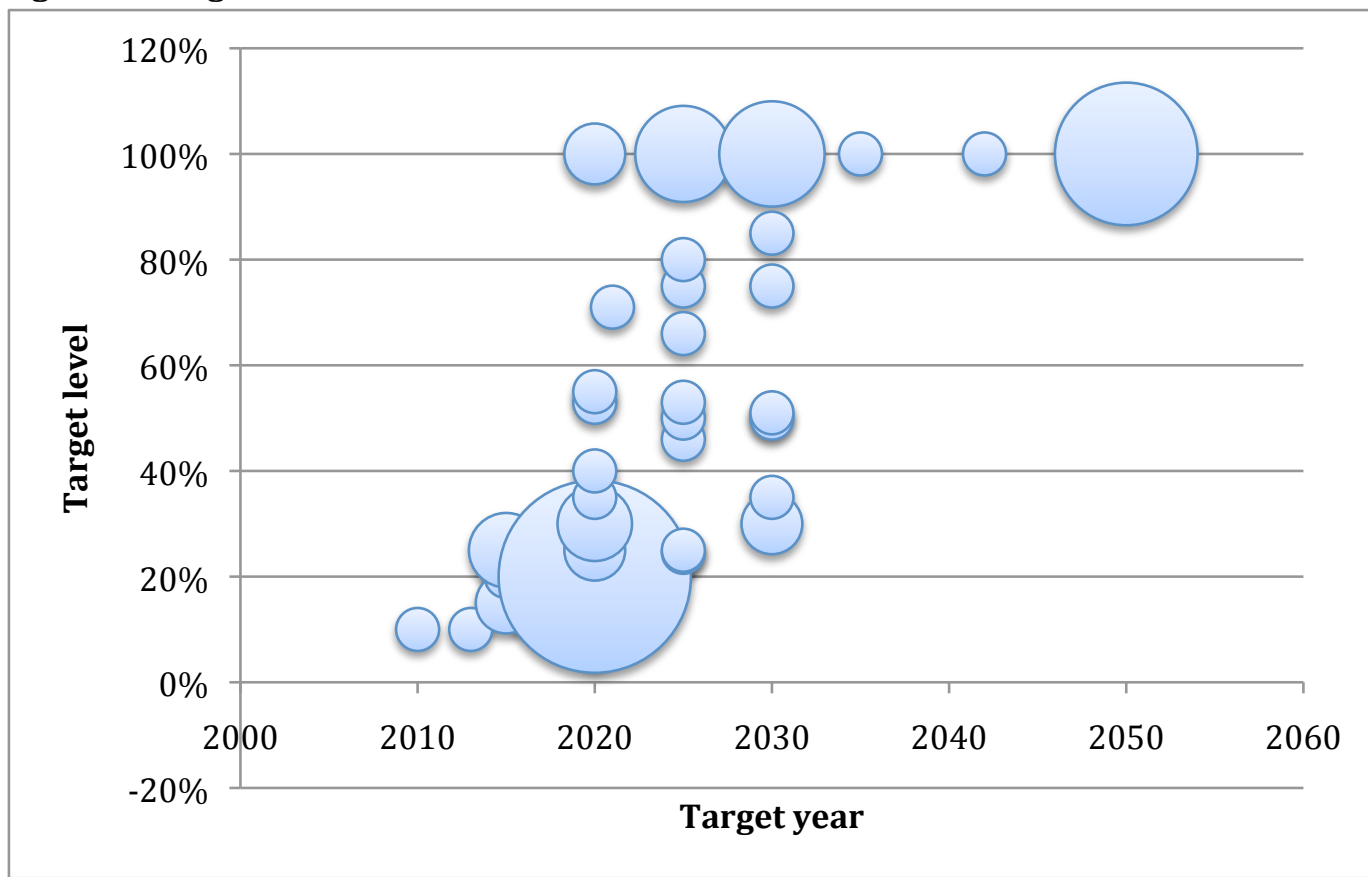

The figure shows GHG emission reduction targets by target level (pct. emission reductions) and target year. The size of the circles indicate the number of municipalities with a particular target. Only GHG emission reduction targets are included in the figure.

The vertical axis shows the target level, the horizontal axis the target year and the number of municipalities determines the size of the circle. Looking at the overall target level the average reduction rate among LG CAPs for the period 2010 to 2020 is $2,78 \%$ p.a. leading to a total reduction for the period of $28 \%$. A $2,78 \%$ annual reduction rate may seem somewhat ambitious, it is however not in line with the national targeted reduction rate of 3,57\% p.a. leading to a $34 \%$ reduction in the 10-year period (The Danish Government, 2013: 27; UNFCCC, 2015). 
When planning for energy system transitions, a long-range target is generally necessary as energy infrastructure is associated with long lead and life times (Scrase \& MacKerron, 2009: 95). Additionally near-term goals tend to be lower as can be seen by the average annual reduction rate for the regions with a larger share of near-term targets $(1,3-1,7 \%)$ compared to the regions with a larger share of long-term targets $(1,6-3,3 \%)$. Near-term goals are generally defined based on an assessment of realistic reductions, whereas long-term goals are defined with regards to necessary reductions. Wheeler found a similar trend among U.S. States adopting both long-term and short-term targets, in which the short-term goals did not put them on track to reach the long-term goals (Wheeler, 2008: 486). Long-term targets, without intermediary goals may conversely fail to produce concrete action, as the time horizon involved lacks impending deadlines, and may not be sufficiently linked to knowledge on concrete mitigation activities. Additionally they tend to be less binding due to the long timeframe and towards 'soft' targets, in the sense that $100 \%$ reduction targets are generally defined as carbon neutrality targets, where a surplus reduction in one sector (e.g. wind power) can compensate for continued use of fossil fuels in another (e.g. transportation). The key objective of a CAP is to initiate action, without which the target level of a CAP is insignificant. For that purpose short-term targets, and even targets less in line with the overall reduction challenge may be just as good, or better, than high long-range targets if they are customized to local mitigation options. The ideal may be a combination of long-range targets and intermediary short-term targets that are in line with the overall reduction target. Thirteen Danish municipalities have a similar combination, without necessarily maintaining a connection between the two. A second distinction can be made between a top-down and a bottom-up approach to target setting. A top-down approach to target setting can be characterized by municipalities defining a reduction target in line with the guidelines of a network membership or following the national target level. This is the case for e.g. the large share of municipalities that are members of the Covenant of Mayors (CoM), sharing the target of $20 \%$ in 2020 in line with CoM guidelines, or the group of Green Cities with the target of 25\% in 2015 in line with their agreements (EUMayors.eu, 2015; Greencities.dk, 2015). Looking at the CoM members $47 \%$ share the 2020 target year and $40 \%$ the $20 \%$ target, constituting two-thirds of all municipalities with a $20 \%$ reduction target, clearly indicating that network memberships affect target level and target year, for the municipalities participating in networks. Conversely a bottom-up approach to target setting takes point of departure in an assessment of the local possibilities for reducing emissions and defines a reduction target in line with the results of this study. Examples of this approach can be found in Solrød and Bornholm municipalities (Solrød, 2009; Bornholm, 2008). Whereas the top-down approach could be said to be more in line with the concept of contributing to national targets, and more in line with establishing long-term targets, the bottom-up approach is generally more in line with local characteristics making it more realistic and likely easier to implement. As for the distinction between longrange and short-term targets a combination of top-down target-setting and bottom-up definition of mitigation action may likely be the ideally integrated approach. 


\subsection{Scope}

Turning subsequently to the scope of local climate action, the available data allow us the possibility of assessing the scope of LG climate action, both in regards to the base year GHG account coverage and whether the action plans include all the aspects necessary in addressing the challenge.

\subsubsection{Base year coverage}

Emissions mapped by local governments by 2010 (CAP GHG accounts) amount to 39,9 Mt, whereas the total Danish emissions reported to the UNFCCC was 62,7 $\mathrm{Mt}$, leaving 22,8 Mt, or approximately one third of the national emissions unaccounted for (UNFCCC, 2015). This is partly due to 16 municipalities not having any GHG accounts and another 3 municipalities having only organisational accounts. These municipalities do however not constitute a large enough group to account for the emissions not included, pointing to gaps in the coverage of the remaining community scope GHG accounts. As can be seen in figure 4 , the energy sectors generally have a high coverage between $72-82 \%$ overall, whereas the non-energy related emissions generally have a significantly lower coverage between 55-42\%. This could be a key factor in explaining the shortfall between local GHG accounts and national emissions, as agriculture alone account for 19\% of Danish emissions in 2012 (Nielsen et al., 2014: 16).

\section{Figure 4: GHG account coverage}

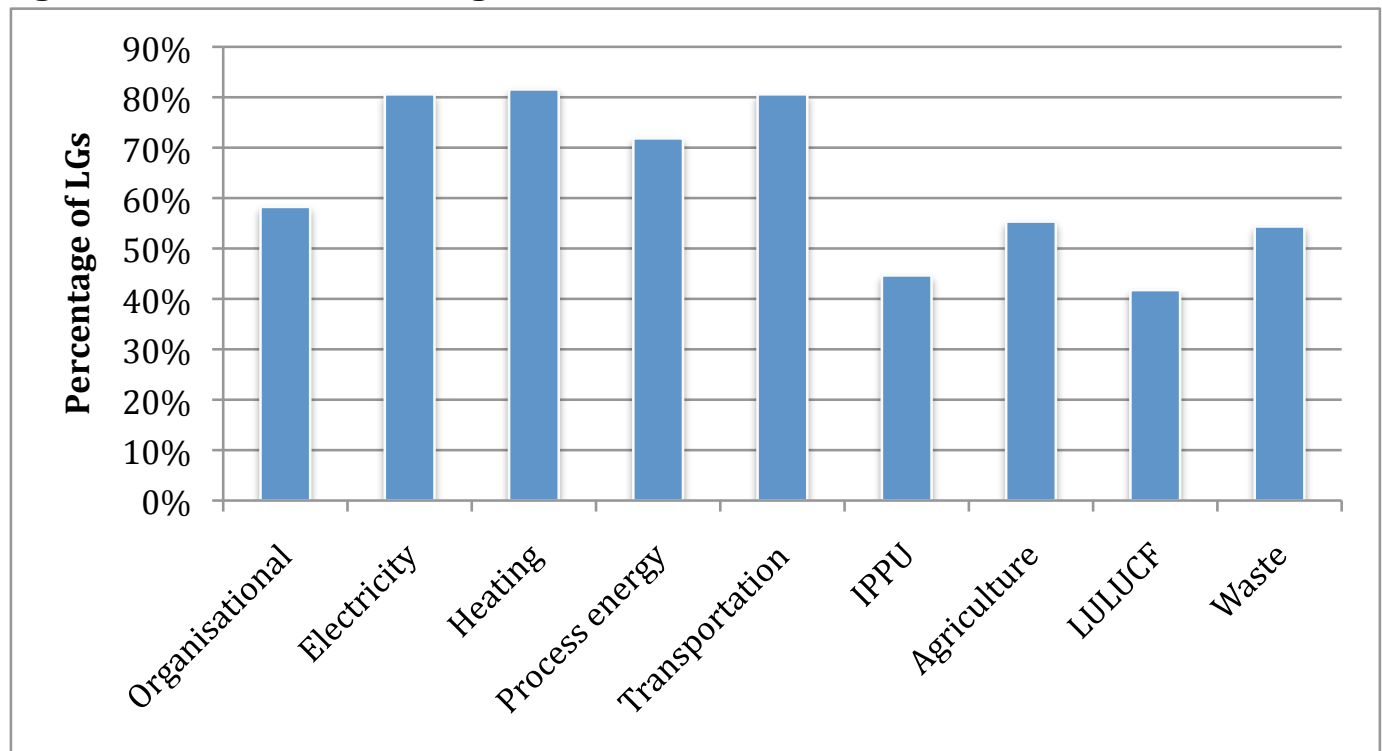

The figure shows the number of local governments (LGs) who included a specific sector in their GHG account. The percentages are calculated as the number of LGs including a particular sector divided by the total number of LGs in Denmark.

The energy sector, has been subdivided into electricity, heating, (industrial) process energy and transportation, waste and IPPU (Industrial Processes and Product Use) sectors are kept in accordance with the latest IPCC guidelines whereas the AFOLU (Agriculture Forestry and Land Use) sector has been split into agriculture and LULUCF (Land Use, Land Use Change \& Forestry), in order to account for the subdivisions in the local accounts (Rypdal et al., 2006: 1.5). According to our survey only $58 \%$ of municipalities include an organisational GHG account in their CAP. As 79\% of municipalities have a climate municipality 
agreement with the Danish Nature Conservation Organization (DN), which require them to account for organisational emissions, this share should be higher (DN, 2015). It is likely that these figures are not published but only submitted to DN and therefore not available to the data collection tools applied. As such we believe that the absence of these accounts does not inhibit the overall validity of the study, only the validity with regards to organisational emissions.

In a survey of municipalities who participate in local climate change programmes in the North-western United States, Rice found that $52 \%$ had conducted a community scope GHG account, and an additional 22\% an operational GHG account, leaving 26\% without any GHG account at the time of the survey (Rice, 2013: 337f). The fact that more than $80 \%$ of all Danish municipalities, not only network members, have an account spanning the key energy sectors, and about half a community account for all sectors speak to the high diffusion of climate action among Danish LGs. The sectoral variation however also confirms Kousky \& Schneider's observation, that municipalities define emissions in varying ways (2003: 363) and the gaps in account coverage are a significant issue if LGs where assigned a more significant role in the mitigation activities. At the same time, however, LG budgets are limited, and the allocation of funds to mapping emissions for sectors in which they have no relevant jurisdiction or mitigation options may be inefficient given that climate change is a largely voluntary policy area (Hoff \& Strobel, 2013: 5). As such the coverage may be warranted under current regulatory conditions, and may indeed be an indicator of customization and a more strategic scoping, focusing available resources on sectors open to LG mitigation activities.

An interesting observation is that the municipalities in the Region of Zealand have a $100 \%$ coverage of all sectors, due in no small part to the joint regional project on mapping and mitigating emissions in cooperation with Roskilde University (Region Zealand, 2011: 2). Similarly, the Central Denmark Region have a high coverage of all the energy sectors, due to a similar regional development project, focused on energy balance sheets and thus energy sector emissions (Olesen, 2011: 3). Regions without similar programs generally have a lower sectoral coverage, indicating the value of cross-municipal and multi-level cooperation in facilitating climate action planning. We find that this highlights the value of cross-scale dynamics and 'nested' approaches in facilitating and coordinating local action (Pasimeni et al., 2014: 168), and that the regional level may hold some of the solutions to combining contextualized action and harmonised approaches and facilitating local action as part of international networks or an integrated national planning system.

\subsubsection{Action plan coverage}

Another key indicator on the scope of LG climate action, are whether the CAP address all the key activities driving emissions. Figure 5 summarize to what extent the LG CAPs include measures targeted the different sectors outlined above, further specified by distinguishing between the different parts of the energy chain for the four energy sectors, as well as adding a category to indicate whether the action plan includes activities targeted energy system properties, such as energy storage and system flexibility in accommodating a larger share of variable energy sources (wind etc.). The overall coverage can generally be found in line with previous studies of LG action plans. Hoff \& Strobel (2013: 7) find that 
energy savings, renewable energy and sustainable transport are by far the largest means of action, as it is in the figure below, and going through the action plans, the most frequent focus area was the municipalities operational activities, as confirmed in several similar studies (Bedsworth \& Hanak, 2013: 668; Sperling et al., 2011: 1342).

\section{Figure 5: Climate Action Plan coverage}

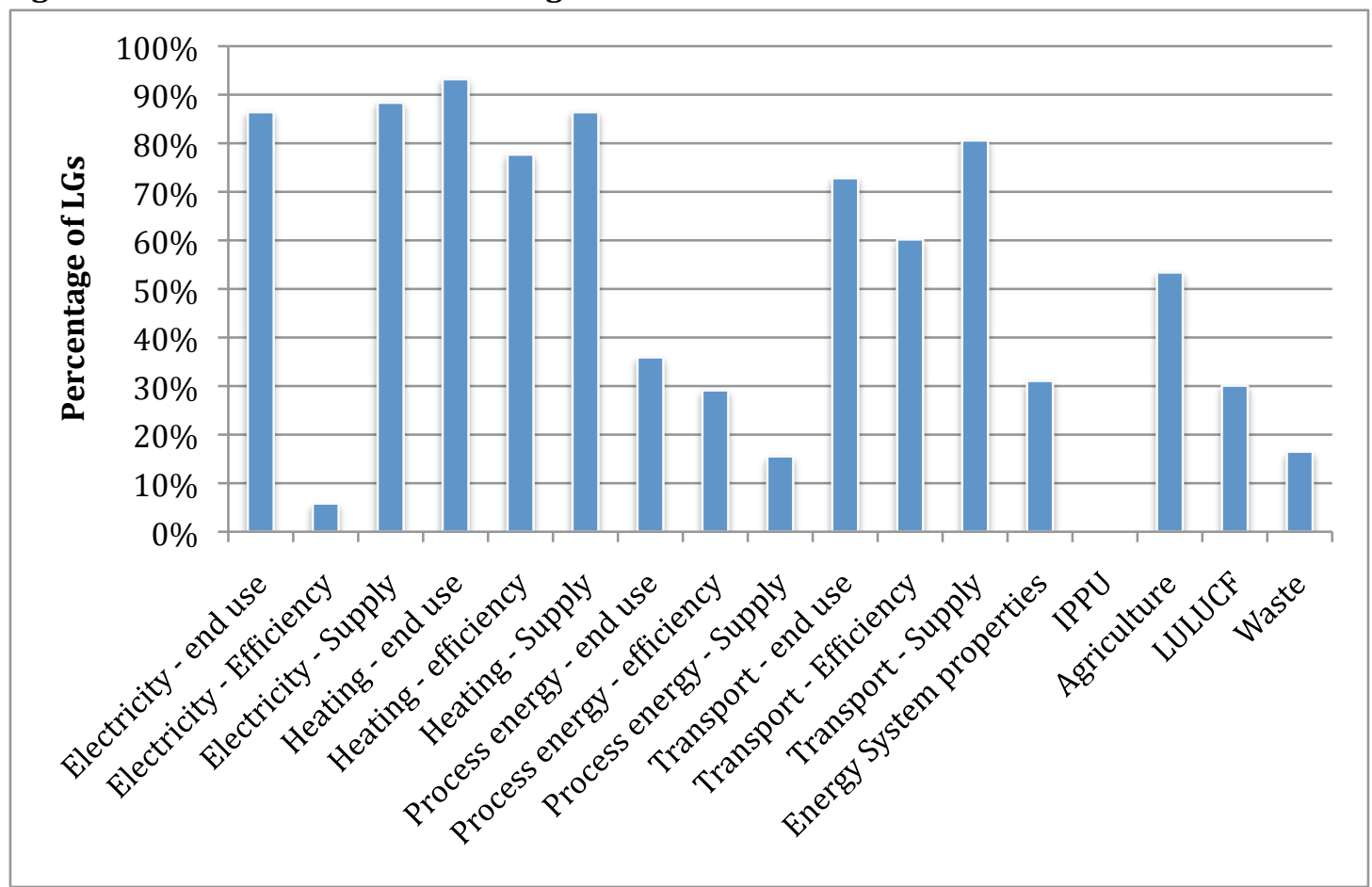

The figure shows the number of local governments (LGs) who included mitigation actions in different focus areas in their CAP. The percentages are calculated as the number of LGs including a particular focus area divided by the total number of LGs in Denmark.

As can be seen in the figure, there is a high degree of variation with regards to what aspects are included in LG CAPs. A clear majority of the action plans include activities targeted electricity, however mainly focusing on energy savings or renewable energy promotion (supply). Conversely, the activities targeting heating include the entire energy chain. The transport and heating sectors, as well as electricity savings and supply have by far the largest concentration among mitigation activities, whereas industry, agriculture, waste and land-use are largely omitted. The variation in CAP coverage can be evaluated based on the modes of governance available to LGs. We can distinguish between governing as a consumer (self-governing), a facilitator (enabling), a supplier (provision) and a regulator (authority) (Corfee-Morlot et al., 2009: 36f). Local authorities in Denmark have a high degree of autonomy with regards to their own operations (consumer), as well as fairly significant local influence on heat and land-use planning (regulator)(Chittum \& Østergaard, 2014: 466; Hoff \& Strobel, 2013: 5). The focus on energy savings could be an indicator of self-governing being a key mode of governance for LGs, heat planning as a result of significant influence on the development of particularly the district heating sector and activities aimed at promoting renewable energy and transport as based on their role as land-use planners (authority) and suppliers of public transportation, utility owners and operators (supplier). In our analysis of LG CAPs we have found a high prevalence 
of all four modes of governance, as $88 \%$ og LGs utilize self-government, 85\% enabling, $81 \%$ provision and $76 \%$ authority measures. This variation may point to a preference for 'soft' measures, or to jurisdictional confusion limiting the use of regulatory policy tools (Hoff \& Strobel, 2013: 5); no matter the reasons the overall sectoral coverage of CAPs will have to be increased if they are to form the backbone of a decentralised governance system.

In addition to the overall sectoral variation, there are some differences, corresponding with the degree of urbanization. While $66 \%$ of rural municipalities include agriculture only $40 \%$ of urban municipalities do so. Conversely the inclusion of transportation efficiency through modal shift increases with the degree of urbanization from $55 \%$ in rural municipalities to $77 \%$ in urban municipalities, indicating that variation may to some extent be a result of the contextual limitations and possibilities in planning action. Although complete coverage is important in avoiding suboptimization, contextual variation and focus is the core argument for localised action. These somewhat conflicting conditions will have to be weighed and joined in a planning framework.

A final key aspect on CAP coverage is the degree to which LG CAPs address the aspects involved in a long-range energy system transition. In a study of 11 Danish CAPs, Sperling et al. find that they insufficiently address issues related to promoting intelligent energy systems, in this study categorized as energy system properties, as this category of action is omitted by a clear majority of LGs (Sperling et al., 2011: 1343f). As can be seen from the figure approximately a third of municipalities across regions include considerations on flexibility and storage in this survey, indicating an improvement but a continued inadequate coverage for the long-term transition. Another indicator of this is the way in which $100 \%$ reduction targets are formulated. Fifteen municipalities have a target of becoming carbon neutral for the entire municipality, and an additional four for the heating and electricity sectors, meaning that they likely intend to produce and export enough renewable electricity each year, to offset the continued use of fossil fuels in transportation. Conversely only five municipalities directly target becoming independent or free of fossil fuels completely. Becoming carbon neutral is a very ambitious target with regards to emission reductions, however it does not address aspects of integrating renewable energy production into a functioning energy system locally, nor the challenges associated with transitioning the more difficult fuel consumptions. A recent survey however concludes that about $60 \%$ of LGs intend to include energy system flexibility in their strategic energy planning towards 2015, showing a continued improvement in considering energy system properties in the longrange (Energiforum, 2014: 7).

\section{Conclusion \& policy implications}

This study has examined the propagation and content of local climate action plans among local authorities in Denmark, with the purpose of discussing the relevance of local action in a national mitigation scheme. Collecting, coding and assessing all available local CAP documents in Denmark, we found a widespread adoption of ambitious CAPs among local authorities, transcending different types of municipalities. The target level, target type and the scope of GHG accounts and mitigation actions was highly varied, in part due to a local framing and 
contextualization of mitigation activities and in part due to a lack of direction and guidelines from the state. We find that the widespread CAP adoption and overall high target levels indicate that local CAPs can act as a relevant contribution to the overall Danish transition.

An integrated national planning framework could advance this contribution. It would however require improvements to the local planning practice. Whereas variation is not a major problem for a voluntary planning task, it would be for a coordinated, obligatory scheme. The quality and uniformity of local CAPs would have to be increased and CAP content and development coordinated horizontally and vertically. If this is to be done without devoting significant resources to enhancing local capacity, it should be a process of continuing improvements based on the current CAPs. An interesting result in this regard is how the regional units can act in facilitating a gradual harmonization and improvement.

While the Danish experience cannot simply be transferred to other national contexts, it can provide some relevant insight. First among these is the necessity of considering the full spectrum of local actors, not simply the pioneers. While international best practice can underpin the activities of frontrunners, it cannot systematically inspire all LGs. Policy experimentation among pioneers holds significant value, but as the mitigation potential of an all-encompassing planning system is far greater, we should focus some attention on how to include a wider group of LGs. Secondly, such a system will have to provide for at better balance between harmonization and contextualization. By tailoring activities to fit more closely to contextual preferences and limitations, mitigation activities can likely be implemented faster and better, while also being integrated into other local hooks (e.g. job creation), thereby increasing the societal value of the activities. Finally both national and local actors pursue climate change mitigation and renewable energy promotion, albeit with different motives and policy tools. By recognising the mutual benefits of an integrated approach, the overall output could be greatly improved, and by pursuing gradual harmonization through regional support mechanisms rather than international standards, improved coverage may not come at the price of overall proliferation.

Due to the nature of the research approach, the study is only able to assess and discuss the content of CAPs. This will naturally leave some aspects open for further research. We find two aspects to be of particular importance. First among these are the means by which we are to assess the performance of local action, i.e. local GHG accounting methodologies. If local actors where to be given additional tasks, continuous performance evaluation would be a key part of any governance scheme, however the variation in accounting approaches and the lack of high quality data sources may inhibit this. Secondly evaluation of CAP implementation performance would be highly valuable in assessing whether local CAPs cover the full range of local activities, and whether implementation activities conform with CAP content. Both aspects are key in furthering the assessment of whether and how LG CAPs are a relevant contribution for state level actors to support.

\section{Acknowledgements}


We would like to thank Dorte Nørregaard Larsen at Energiforum Danmark for sharing their data, Esbern Holmes for assistance with GIS, the reviewers for helpful comments in improving the script and the countless planners in Danish municipalities, regions, utilities and other organizations who have consistently supported our work, as well as Roskilde University for funding the research. The usual disclaimers apply.

\section{Appendix A. Coding Manual}

The coding manual contained in table A.1 has been utilised in the content analysis of the LG CAPs. All 436 documents have been reviewed and added to a coding scheme in which each category below corresponds with a column. Each LG is given a separate row, in which values from all the documents published by a given LG is combined. Only a selection of the coded values of key relevance for the topic at hand has been utilized in this article.

Table A.1: Coding Manual

\begin{tabular}{|c|c|}
\hline Category & Values \\
\hline LG CAP presence & Yes/No \\
\hline Number of documents & Number \\
\hline \multicolumn{2}{|l|}{ Target } \\
\hline Quantified target & Yes/No \\
\hline Primary GHG target & Percentage \\
\hline Primary target year & Year \\
\hline Secondary GHG target & Percentage \\
\hline Secondary target year & Year \\
\hline Organisational GHG target & Percentage \\
\hline Organisational target year & Year \\
\hline Renewable energy target & Percentage \\
\hline Renewable energy target year & Year \\
\hline Base year & Year \\
\hline Base year emissions & Tons of $\mathrm{CO}_{2}$-eq \\
\hline Target year emissions & Tons of $\mathrm{CO}_{2}-\mathrm{eq}$ \\
\hline Reduction target & Tons of $\mathrm{CO}_{2}-\mathrm{eq}$ \\
\hline Other target & Yes/No \\
\hline Organisational scope & Yes/No \\
\hline Community scope & Yes/No \\
\hline \multicolumn{2}{|l|}{ Plan elements } \\
\hline GHG account & \multirow[t]{8}{*}{ Number for each element } \\
\hline Baseline projection & \\
\hline Scenario analysis & \\
\hline Assessment of resource/savings potential & \\
\hline Action Plan & \\
\hline Heat plan & \\
\hline Windmill plan & \\
\hline Other Analysis & \\
\hline \multicolumn{2}{|l|}{ Tool application } \\
\hline GHG account tools & \multirow{6}{*}{$\begin{array}{l}\text { For each plan element applied tools are indicated } \\
\text { by: } \\
\text { A=CO2-calculator } \\
B=\text { Rambøll approach } \\
\text { C= RUC Approach } \\
D=\text { SEP Manual } \\
\text { E= SEAP Manual } \\
\text { F= Energy balance sheet (PlanEnergi) }\end{array}$} \\
\hline Baseline projection tools & \\
\hline Scenario analysis tools & \\
\hline Potential assessment tools & \\
\hline Action plan tools & \\
\hline Other tools & \\
\hline
\end{tabular}




\begin{tabular}{|c|c|}
\hline & $\begin{array}{l}\text { G=DSN Approach (Region of Southern DK } \\
\text { approach) } \\
\text { H= LEAP } \\
\text { I=Other } \\
\text { J=EnergyPLAN model } \\
\text { K=Stream model } \\
\text { U=Unclear }\end{array}$ \\
\hline \multicolumn{2}{|l|}{ GHG account coverage } \\
\hline Electricity & \multirow{8}{*}{$\begin{array}{l}\text { Whether the sector is included is indicated by } \\
1 / 0 / \mathrm{U} \text { for Yes/No/Unclear }\end{array}$} \\
\hline Heating & \\
\hline Process energy & \\
\hline Transportation & \\
\hline IPPU & \\
\hline Agriculture & \\
\hline LULUCF & \\
\hline Waste & \\
\hline \multicolumn{2}{|l|}{ CAP coverage } \\
\hline Electricity - end use & \multirow{17}{*}{$\begin{array}{l}\text { Whether the activity is included is indicated by } \\
1 / 0 / \mathrm{U} \text { for Yes/No/Unclear }\end{array}$} \\
\hline Electricity - efficiency & \\
\hline Electricity - supply & \\
\hline Heating - end use & \\
\hline Heating - efficiency & \\
\hline Heating - supply & \\
\hline Process energy - end use & \\
\hline Process energy - efficiency & \\
\hline Process energy - supply & \\
\hline Transport - reduction & \\
\hline Transport - modal shift/efficiency & \\
\hline Transport - Fuel switch & \\
\hline Energy system properties & \\
\hline IPPU & \\
\hline Agriculture & \\
\hline LULUCF & \\
\hline Waste & \\
\hline \multicolumn{2}{|l|}{ Modes of governance } \\
\hline Self-governing & \multirow{4}{*}{$\begin{array}{l}\text { Whether the mode of governance is applied is } \\
\text { indicated by Yes/No/Unclear }\end{array}$} \\
\hline Governing through enabling & \\
\hline Governing through provision & \\
\hline Governing by authority & \\
\hline
\end{tabular}

\section{References}

AALL, C.; K Groven \& G. Lindseth (2007) The scope of Action for Local Climate Policy: The case of Norway. In "Global Environmental Politics", vol. 7, no. 2, pp. 83-101.

ANDERSEN, I. (2010) Den skinbarlige virkelighed - om vidensproduktion inden for samfundsvidenskaberne. $4^{\text {th }}$ edition. Samfundslitteratur, Frederiksberg (DK).

$\mathrm{BAI}, \mathrm{X}$. (2007) Integrating Global Environmental Concerns into Urban Management. The scale and Readiness Arguments. In "Journal of Industrial Ecology", vol. 11, no. 2, pp. 15-29.

BEDSWORTH, L.W. \& E. Hanak (2013) Climate policy at the local level: Insights from California. In "Global Environmental Change, vol. 23, pp. 664-677.

BORNHOLM (2008) The path to an Even More Sustainable Bornholm - 2025 Energy Strategy for Bornholm. 
BULKELEY, H. \& M. Betsill (2005) Rethinking Sustainable Cities: Multilevel Governance and the 'Urban' Politics of Climate Change. In, "Environmental Politics", vol. 14, no. 1, pp. 42-63.

BulKeLEY, H. (2010) Cities and the Governing of Climate Change. In "The Annual Review of Environment and Resources", vol. 35 pp. 229-253.

BulKeley, H. (2013) Cities and Climate Change. $1^{\text {st }}$ Edition, Routledge, Abingdon (UK).

BROTO, V.C. \& H. Bulkeley (2013) A survey of urban climate change experiments in 100 cities. In "Global Environmental Change", vol. 23, pp. 92-102.

CARBOnN (2014) carbonn Climate Registry. User Manual. For cCR v.4.1. - October 2014

Chiтtum, A. \& P.A. Østergaard (2014) How Danish communal heat planning empowers municipalities and benefits consumers. In "Energy Policy", vol. 74, pp. 465-474.

CoEnEN, L.; P. Benneworth \& B. Truffer (2012) Towards a spatial perspective on sustainability transitions. in "Research Policy", vol. 41, pp. 968-979.

CONCITO (2010) Kommunernes klimaindsats. June 2010. [The Municipalities climate change efforts].

CorfeE-Morlot, J.; L. Karmal Chaoui, M.G. Donovan, I. Cochran, A Robert \& P.J. Teasdale (2009) Cities, Climate Change and Multilevel Governance. OECD Environment Working Papers No. 14, 2009, OECD Publishing, OECD; Paris (France).

Crossley, D. \& B. Sørensen (1983) Creating energy futures: A short guide to energy planning. Energy series No. 8, Roskilde University.

DANISH GEODATA AGENCY (2015) Kort10. (topographic map showing Denmark in $1: 10,000)$. Information on the data: http://eng.gst.dk/mapstopography/topographic-data/denmark-110-000/\#.VVBtf2CFMyI

Terms of use:

http://eng.gst.dk/media/gst/2364686/Conditionsforuseofopenpublicgeographicda ta.pdf

DIXON, T. \& E. Wilson (2013) Cities' low-carbon plans in an 'age of austerity': an analysis of UK local authority actions, attitudes and responses. In "Carbon Management", vol. 4, no. 6, pp. 663-680.

DJF (2007) Landdistriktskommuner - Indikatorer for landdistrikt. [Rural municipalities - indicators of rural areas]. Danmarks JordbrugsForskning (Danish Institute of Agricultural Sciences).

DN (2015) Klimakommuner. The Danish Nature Conservancy Organisations website on Climate Municipalities: http://www.klimakommuner.dk (2015-02-18). [Climate Municipalities]

ENERGIFORUM (2014) Kortlægning af kommunernes arbejde med strategisk energiplanlægning. January 2014. [Mapping the Municipalities work with strategic energy planning].

EUMAYORS.EU (2015) The Covenant of Mayors. Covenant of Mayors website: http://www.covenantofmayors.eu/about/covenant-of-mayors en.html (2014-0123).

EUMAYORS.EU (2015B) Signatories. Covenant of Mayors website: http://www.covenantofmayors.eu/about/signatories en.html?q=Search+for+a+Sig natory...\&country search=dk\&population $=$ \&date of adhesion=\&status $=(2015-08$ 17).

FUDGE, S. \& M. Peters (2009) Motivating carbon reduction in the UK: the role of local government as an agent of social change. In "Journal of Integrative Environmental Sciences", vol. 6, no. 2, pp. 103-120.

GHG Protocol (2015) Mitigation Goal Standard. An accounting and reporting standard for national and subnational greenhouse gas reductions.

GIDDEns, A. (2009) The politics of Climate Change. Polity Press, Cambridge (UK). 
Gore, C.D. (2010) The Limits and Opportunities of Networks: Municipalities and Canadian Climate Change Policy. In "Review of Policy Research", vol. 27, no. 1, pp. $27-46$.

GreEnCITIES.DK (2015) Klima. Green Cities website: http://www.greencities.dk/Klima/ (2015-01-23).

GreEnCITIES.DK (2015в) Green Cities. Green Cities website: http://www.greencities.dk (2015-08-17).

HofF, J. \& B.W. Strobel (2013) A Municipal 'Climate Revolution'? The shaping of Municipal Climate Change Policies. In "The Journal of Transdisciplinary Environmental Studies" vol. 12, no. 1, pp. 3-14.

HoLM, J. (2007) Eksperimenter I lokalsamfundets miljøomstilling - 12 års local agenda 21-arbejde I Danmark. In J. Holm, L.K. Petersen, J. Læssøe, A. Remmen \& C.J. Hansen [Eds.] “Økologisk modernisering på dansk - brud og bevægelser I miljøindsatsen", 1'st Edition, Frydenlund, Copenhagen (DK).

KERN, K. \& G. Alber (2008) Governing Climate Change in Cities: Modes of Urban Climate Governance in Multi-level Systems. In "Competitive Cities and Climate Change", OECD Conference Proceedings, Milan, Italy, 9-10 October 2008, Chapter 8, Paris: OECD, pp. 171-196.

KoUSKY, C. \& S.H. Schneider (2003) Global climate policy: will cities lead the way? In "Climate Policy", vol. 3, pp. 359-372.

Kramers, A.; J. Wangel, S. Johansson, M. Höjer, G. Finnveden \& N. Brandt (2013) Towards a comprehensive system of methodological considerations for cities' climate targets. In "Energy Policy", vol. 62, pp. 1276-1287.

LAFFERTY, W.M. (2001) Sustainable Communities in Europe, Earthscan, London (UK).

LUTSEY, N. \& D. Sperling (2008) America's bottom-up climate change mitigation policy. In "Energy Policy", vol. 36, pp. 673-685

LGDK (2009) Kommunernes klimaudspil - opgaverne fordeles. [Municipalities Climate Initiative - the Tasks are Distributed] Part 2. Local Government Denmark, 1. Edition.

MINISTRY OF HOUSING, URBAN \& RURAL AFFAIRS (2012) Regional- og landdistriktspolitisk redegørelse 2012. [Regional and rural policy report 2012].

MM (2010) Hver tredje dansker bor i en grøn superkommune. [Every third Dane lives in a green super municipality], In "Ugebrevet Mandag Morgen" [Monday Morning Weekly], August 16 ${ }^{\text {th }} 2010$, pp. 16-20.

MusCo, F. (2010) Policy Design for Sustainable Integrated Planning: From Local Agenda 21 to Climate Protection. In M. van Staden \& F. Musco [Eds.] "Local Governments and Climate Change", $1^{\text {st }}$ Edition, Springer, Dordrecht (NL)

NiELSEN, O.-K., Plejdrup, M.S., Winther, M., Nielsen, M., Gyldenkærne, S., Mikkelsen, M.H., Albrektsen, R., Thomsen, M., Hjelgaard, K., Hoffmann, L., Fauser, P., Bruun, H.G., Johannsen, V.K., Nord-Larsen, T., Vesterdal, L., Møller, I.S., Caspersen, O.H., Rasmussen, E., Petersen, S.B., Baunbæk, L. \& Hansen, M.G. (2014) Denmark's National Inventory Report 2014. Emission Inventories 1990-2012 - Submitted under the United Nations Framework Convention on Climate Change and the Kyoto Protocol. Aarhus University, DCE - Danish Centre for Environment and Energy, 1214pp. Scientific Report from DCE - Danish Centre for Environment and Energy. http://dce2.au.dk/pub/SR101.pdf

OLESEN, J. (2011) Energi- og klimaregnskab for Region Midtjylland. Presentation. PlanEnergi \& Central Denmark Region, March 2nd, 2011. [Energy and climate account for the Central Denmark Region].

PAsimeni, M. R.; I. Petrosillo, R. Aretano, T. Semeraro, A. De Marco, N. Zaccarelli \& G. Zurlini (2014) Scales, strategies and actions for effective energy planning: $A$ review. In "Energy Policy", vol. 65, pp. 165-174. 
PITT, D. \& E. Bassett (2014) Collaborative Planning for Clean Energy Initiatives in Small to Mid-Sized Cities. In "Journal of the American Planning Association", vol. 79, no, 4, pp. 280-294.

REGION ZEALAND (2011) Drivhusgasserne i Region Sjælland - Opgørelse af udledningen af drivhusgasser. September 2011. [GHG in the Region of Zealand GHG inventory].

RICE, J.L. (2013) Public Targets, Private Choices: Urban Climate Governance in the Pacific Northwest. In "The Professional Geographer", vol. 66, no. 2, pp. 333-344.

RKSK (2011) Energi2020. [Energy2020]. Ringkøbing-Skjern (RKSK) municipality.

RYPDAL, K.; N. Paciornik, S. Eggleston, J. Goodwin, W. Irving, J. Penman \& M. Woodfield (2006) Chapter 1 - Introduction to the 2006 Guidelines, In "Volumne 1: General Guidance and Reporting" by S. Eggleston, L. Buendia, K. Miwa, T. Ngara \& K. Tanabe [Eds.]. The 2006 IPCC Guidelines for National Greenhouse Gas Inventories (IPCCNGGIP).

SALON, D.; S. Murphy \& G.C. Sciara (2014) Local climate action: motives, enabling factors and barriers. In "Carbon Management", vol. 5 no. 1 pp. 67-79

SAUTER, R. \& D. Bauknecht (2009) Distributed generation: Transforming the Electricity Network. In I. Scrase \& G. MacKerron [Eds.] "Energy for the Future - A New Agenda". Palgrave Macmillan, Basingstoke (UK).

SCHARPF, F.W. (1993) Coordination in Hierarchies and Networks. In: ibid. (ed.). "Games in Hierarchies and Networks". Frankfurt a.M.: Campus, 125-165

SCRASE, I. \& G. MacKerron (2009) Lock-In in "Energy for the Future", I. Scrase \& G. MacKerron [Eds], Palgrave Macmillan, New York (USA).

SMIL, V. (2010) Energy Transitions. History, Requirements, Prospects. 1. Udgave, 2010. Praeger, Santa Barbara (USA).

SOLRøD (2009) Klimaplan for Solrød Kommune 2010-2025. [Climate Action Plan for Solrød Municipality 2010-2025].

SPERLING, K.; F. Hvelplund og B.V. Mathiesen (2011) Centralisation and decentralisation in strategic municipal energy planning in Denmark. In "Energy Policy" vol. 39 pp. 1338-1351.

ST. DENIS, G. \& P. Parker (2009) Community energy planning in Canada: The role of renewable energy. In "Renewable and Sustainable Energy Reviews", vol. 13, pp. 2088-2095.

The Danish Government (2013) The Danish Climate Policy Plan. Towards a low carbon society.

THISTED (2009) Helhedsorienteret energipolitik for Thisted Kommune. [Holistic energy policy for Thisted municipality].

TÅRNBY (2010) Klimahandlingsplan 2010-2011 [Climate Action Plan 2010-2011).

UN (1992) Earth Summit Agenda 21 - The United Nations Programme of Action from Rio. United Nations Publication no. E.93.I.11

UN (1997) S/19-2. Programme for Further Implementation of Agenda 21.

UN (2002) Plan of Implementation of the World Summit on Sustainable Development.

UN (2012) 66/288. The future we want.

UNFCCC (2015) Greenhouse gas inventory data - detailed data by party. United Nations Framework Convention on Climate Change website: http://unfccc.int/di/DetailedByParty/Event.do?event=go (August 31, 2015).

WhEeler, S.M. (2008) State and Municipal Climate Change Plans - The First Generation. In "Journal of the American Planning Association", vol. 74, no. 4, pp. 481-496.

WILBANKS, T. J. \& R. W. Kates (1999) Global change in local places: How scale matters. In "Climatic Change" vol. 43, pp. 601-628. 